\title{
A Critical Risk Analysis of Absenteeism in the Work Place
}

\author{
Reuben Mokwena Badubi \\ School of Management, Wuhan University of Technology, Wuhan, P.R. China
}

\begin{tabular}{|c|c|}
\hline & \\
\hline $\begin{array}{l}\text { DOI: } 10.18775 / \text { jibrm.1849-8558.2015.26.3004 } \\
\text { URL: } \underline{\text { http://dx.doi.org/10.18775/jibrm.1849- }} \\
\text { 8558.2015.26.3004 }\end{array}$ & \multirow{2}{*}{$\begin{array}{l}\text { This study seeks to validate the fact that there is a problem of absenteeism amongst employees } \\
\text { in different workplaces and analyzes the impact of a persistent absenteeism by employees on } \\
\text { the organization. Employees can be absent at work for various reasons or just deciding to be } \\
\text { rebellious as a sign of registering some concerns especially associated with job dissatisfaction } \\
\text { in the workplace. Absenteeism in the workplace is catastrophic as it hinders performance and } \\
\text { results. Organisations, therefore, should put mechanisms in place that would be geared towards } \\
\text { curbing this rampant attitude that should not be entertained. The researcher in this article, } \\
\text { based on a narration and assembly of several kinds of literature, explore and expound the types } \\
\text { of absenteeism and what influences employees to stay away from work as well as solution to } \\
\text { arrest the situation. There is a need for management to countermeasure issues of absenteeism } \\
\text { because they impact negatively to the finances, an image of the organization and derail } \\
\text { progress too. A qualitative approach was considered when compiling this paper in order to } \\
\text { analyse the topic. }\end{array}$} \\
\hline $\begin{array}{l}\text { Keywords: } \\
\text { Absenteeism, Performance, Organizations, Job } \\
\text { satisfaction, Habitual }\end{array}$ & \\
\hline
\end{tabular}

\section{Introduction}

Absenteeism is every manager's nightmare, and organisations should periodically calculate the cost of absenteeism to enable managers to determine the seriousness of the problem and its impact on profits based on the most recent available data (Grobler, Warnich, Carrell, Elbert, and Hatfield (2006, p.123). In order to effectively control and manage absenteeism at the workplace, it is important to define the concept well, distinguish between the different types of absenteeism (Nel, Werner, Haasbroek, Poisat, Sono, and Schultz 2008, p581), and look at the direct and indirect cost associated with absenteeism (Levy 2006, p.321). Employees are required by their employment contract and/or common law duty to regularly and reliably attend their place of work. When they fail to do so, this constitutes an incidence of absenteeism. Absenteeism is generally harmful to an organisation, but in some instances, not having an employee show up at work would be preferable to having them there; consider, for example, the possibly disastrous consequences of having an ill or fatigued pilot or surgeon perform their work. Employees present a variety of excuses for these short-term absences, for example, their car has broken down, or they have to appear in court as a witness. Supervisors need to discern the authenticity of the excuse before granting it. The absenteeism policy must make clear what constitutes authorised absenteeism, and supervisors must adhere to the policy when granting such leave. The question to be addressed in this study is whether employees absenteeism has negative impact on the performance of organisations.

\section{Absenteeism}

Swarnalatha and Sureshkrishna (2013, p.1) define absenteeism simply as the "failure to report to work" and suggest that employees who regularly or habitually absent from their workplace are a threat to the organisation and turn it into a "deviant workplace". Senel and Senel (2012, p.1144) take a more measured approach, defining absenteeism as the "lack of presence of an employee for planned work". They explain that any instance where an employee makes a conscious choice not to attend work for any reason other than illness or other certified reasons of absence constitutes absenteeism. The above definitions of absenteeism exclude absences from work that are planned or approved in advance and which are not as disruptive as those that arrive without warning. Planned absences from work allow managers to make contingency arrangements and implement them in advance. It is important to distinguish between authorised absences (planned and managed absenteeism) and unplanned ones, which are unpredictable both regarding the duration of the incident and the person involved - absenteeism that is unplanned, disruptive and costly. This type of absenteeism is held in such universal disdain that is often referred to as 'culpable absenteeism', reflecting the blameworthiness of an employee who is absent without authorisation for reasons that are within his control. According to Nel, et al. (2008), excessive authorised absence is reflective of a permissive organisational culture where employees are likely to abuse the high degree of flexibility. Delinquent sick leave offers a case in point. If an employee routinely calls in sick just before or after a weekend, long weekend or public holiday, it should send out alarm signals to his supervisor or manager. Levy (2006) points out that it is, at the very least, suspicious that medical conditions should present with such regularity and reliability at these times. A simple check of an employee's absence record will enable an employer to distinguish between genuine sick leave cases and instances of sick leave abuse. Delinquent sick leave tends to fall into a recognisable, repetitive pattern, often on the same days of the week, while genuine cases of illness 
arise much more randomly and are normally of a longer duration. Although blatant abuse of sick leave is relatively easy to identify and deal with (Levy 2006), it is a pervasive and ubiquitous organisational ill. In a UK-based study on the abuse of sick leave, $40 \%$ percent of respondents admitted that, at one time or another, they had taken sick leave when they were not ill. Of this $40 \%, 7 \%$ indicated that they resorted to such behaviour often or all the time (Levy, 2006). Measuring the cost of absenteeism is no simple task. In 2008, Smanjak reported an unscheduled absenteeism rate of approximately $9 \%$ among hourly-paid workers in the United States (Smanjak, 2008). This means that almost one in every ten employees is absent when they are required to be at work. Smanjak (2008), in a recent study, found that the average direct cost of unscheduled absenteeism to US employers is USD789 per employee per year. Robbins and Judge (2004, p.28) affirm that organisations that rely heavily on assembly-line production are vulnerable to disruption from aboveaverage absenteeism rates (higher than 3\%), as the direct and indirect costs associated with absenteeism will ultimately result in delayed decision-making, strained relations with customers due to poor product quality, and late deliveries. They stress that organisations should have policies and measures in place to prevent absenteeism from becoming a burden and rendering them to be dysfunctional. A culture of absenteeism must be actively discouraged.

According to Grobler and colleagues' process model on the major influences of absenteeism, an employee's attendance motivation, on the one hand, and ability to attend, on the other, is the two primary drivers of employee absenteeism (Grobler et al. 2006, p.124). Kaman (1995, p.133) lists three diverse but highly interrelated variables that play a major role in absenteeism, namely personal, attitudinal and organisational factors. The most significant personal characteristics vis-à-vis employee absences are an employee's gender, age and occupational status. Schultz and Schultz (2006) suggest that younger workers are much more inclined to take unauthorised leave than their older counterparts. According to Kaman (1995, p.238), younger employees have higher absence rates, but as employees approach middle age, the rate decreases; Kaman adds that the second rise in absenteeism rates may be observed after the age of 50 years due to an increase in debilitating diseases from this age onward. Attitudinal characteristics include dissatisfaction with work, which is a major determinant of employee absenteeism. Nel et al., (2008) explains that an employee may have certain expectations about the application and development of his skills and receiving respect and equal treatment. If these expectations are not met, the employee may resort to abusing sick leave as a means of seeking a temporary withdrawal from the work situation (Nel et al., 2006). Nel et al. also mention a poor job-person fit as a source of dissatisfaction that may give rise to absenteeism. The third variable mentioned by Kaman relates to organisational factors, for example, a permissive organisational culture might encourage employee absence (Nel et al., 2006). The size of the work unit is very important in this regard: as it increases, so too does absenteeism, and vice versa (Kaman, 1995, p.239).

\subsection{Measuring Absenteeism}

Measuring the level of absenteeism among its employees enables an organisation to determine the extent and nature of the problem to take appropriate corrective action. Two commonly used methods for measuring absenteeism are based on total work time lost due to absenteeism and the frequency of absence, respectively. The time lost method expresses the percentage of contracted working time available (in days or hours) that has been lost due to absence (Nel et al. 2001). The absence frequency approach for reporting absence data expresses the average number of absence events per employee as a percentage. It measures the spread of absence across employees and provides a better indicator of short-term absence than the time lost method.

An 'absence incident' refers to any instance of absence, regardless of its duration. A higher absence incident rate indicates that absences are of shorter duration and, therefore, more disruptive to the organisation, as it is easier and less costly to make contingency plans when it is known that an employee will be absent for a longer period than it is to deal with short unexpected absences.

\subsection{Impact of Absenteeism}

The Confederation of British Industry (CBI) reports that absenteeism among manual workers results in delayed production, lower quality levels, disruption of workflow, low morale and general dissatisfaction, all of which lead to lower productivity. Goodman and Atkin (1994), also found that replacing an absent worker with a less skilled worker, either from within the organisation or outside, leads to a decline in productivity, and emphasise disciplinary action and an increase in workplace accidents among other negative impacts. However, Robbins and Judge (2004, p.28) point out that absenteeism may have negative and positive consequences for an organisation. On the negative side, they also cite the impact of lost production and a reduction in work quality; on the positive, they mention the benefit that may be derived from a fatigued employee's absence when the nature of their work requires mental alertness (Robbins and Judge, 2004, p.28). Goodman and Atkin (1994, p.279) support this view, saying that the impact depends on the constituency under consideration. While Coughlan (2004) does not mention any positive outcomes associated with absenteeism, she also agrees that the impacts are multifaceted, emphasising that they are not limited to production losses or inferior outputs - which may eventually translate into a potential loss of clients but also have an immediate effect on an absentee's colleagues and managers. Coughlan's opinion is borne out by a study where interviewees asserted that everyone, from co-workers to supervisors and departmental managers, who works with an absent employee, is affected by every incident of absence (McHugh, 2001). In particular, respondents frequently reported that co-workers who were required to step in for their absent colleagues experienced increased pressure and stress. Moreover, workers who have been absent from work will return to an increased workload, which in turn leads to increased work pressure, making them susceptible to further absence from work (McHugh 2001). Studies about the impact of absenteeism in school environments report similar findings. According to Arnell and Brown (2012, p.172), the colleagues of an absent teacher "tend to feel more burdened, because they may have to plan for the teacher who is absent". Also, "substitute teachers do not always measure up to the regular classroom teacher's routine and methods to stimulate students to learn", which will result in lower motivation and morale among students and concomitant poorer performance. Considering the above information, it is evident that absenteeism seriously affects the individual and his or her colleagues, management, the organisation as a whole and even the community at large.

\subsection{Reasons for Absenteeism}

The excessive non-attendance or habitual late-coming of an employee may speak volumes about both the employee involved and the organisation itself and always bears further investigation. While employees may have legitimate reasons for being absent from work, such as illness or personal problems, the organisation may also tacitly encourage this behaviour through its actions or in action. The following factors have been found to contribute to absenteeism:

- Family responsibilities: Vloebergs (2002), states that research has shown that employees nowadays seem to value the quality of life for the 
amount of salary they receive. People want more control over their work life and accord more meaning to their non-work life. Family responsibilities may keep devoted parents away from work, especially mothers - for example, they need to prepare their kids for school in the morning or take care of them when they're ill. Balancing work and family life must, therefore, be an important management issue. Organisations may devise different methodologies to achieve this, for example, flexitime, telecommuting, providing childcare centres within the organisation or enabling parents to work from home. Working from home is however not practicable for teachers, as they need to interact with learners.

- Pregnancy and maternity leave: Pregnant women may be absent from work to attend routine medical check-ups, while maternity leave provides for relatively prolonged absences from work for new mothers. The education policy in Botswana allows for twelve weeks of maternity leave. However, paternity leave is not recognised in Botswana education system as well as labour laws.

- Minor illnesses: Ailments such as colds, flu and headaches may afflict employees to such an extent that they elect to miss work in order to seek medical attention.

- Acute medical conditions: Serious medical conditions such as HIV/Aids, cancer, stroke and heart attack may require sufferers to follow a strict medical regimen, such as regularly going for check-ups or taking medication with debilitating side-effects that may prevent them from going to work.

- Injuries: Regardless of whether injuries occur at the workplace or elsewhere, affected employees may not be able to perform their normal duties or even go to work.

- Stress: Many researchers have labelled teaching a highly stressful profession (Al-fudail \& Mellar 2008). Liu and Ramsey (2008) found that stress due to poor work conditions - for example, inadequate classrooms or equipment and the (perceived or real) danger of physical violence to their persons - strongly influence teachers' job satisfaction levels. The researchers further report that inadequate time-planning and preparation and a heavy teaching load also reduce the satisfaction that educators may otherwise glean from their profession. The problem is further compounded by the demands of administrators, colleagues, students and parents, students behaviour, as well as failure to recognise their achievements (Greenglass \& Burke, 2003). Over time, the cumulative effect of these stressors and the negative emotions they engender may lead teachers to absent themselves in order to recuperate and restore their physical and mental energy levels (Kyriacou 2001). This is not only highly relevant to teachers but is also true of school administrators and policymakers.

- Burnout and fatigue: According to Maslach (2003), a phenomenon that can be psychological, and can involve persistent responses and stressrelated issues in the workplace is known as burnout. It is therefore conceptualised and associated with prolonged work-related stress, within employees who have direct contact with other people from different portfolios or other. It may also result from ongoing work overload or work prolonged hours without rest. Organisations that are understaffed may have a higher incidence of burnout among employees.

- Alcohol- or drug-related conditions: Recognising an alcoholic at work can be difficult. It may take a medical expert to spot the early symptoms of alcoholism, such as habitual tardiness, as they are often related to other problems, such as absenteeism. Employees who habitually overindulge or are addicted to drugs may experience incapacitating hangovers that prevent them from going to work or might resort to staying away from work in order to avoid having their problem detected, seeking refuge in sick leave. Alcohol or drug addiction is a serious problem and organisations should have a formal written policy on substance abuse in place to properly address it (Nel et al. 2006, p.295).

- Bad weather and transport problems: Extreme weather conditions, such as floods or heavy snow, may make roads impassable or trap people in their homes, making it impossible for them to go to work. Unreliable transport, or strikes in the public transport system, may likewise keep employees from work.

- Labour disputes or lockouts: Labour disputes and strike action may compel employees to stay away from the workplace or may result in a lockout situation, where the employer refuses workers entry. Section 213 of the South African Labour Relations Act (Act 66 of 1995) defines 'lockout' as the exclusion by an employer of employees from the employer's workplace, for the purpose of compelling the employees to accept a demand in respect of any matter of mutual interest between employer and employee, whether or not the employer breaches those employees' contracts of employment in the course of or for that exclusion. On April 18, 2011, public servants belonging to the Botswana Federation of Unions, enjoying a base of 90000 members, went on strike demanding higher salaries in the first ever militant strike in Botswana since independence. They decided to stay away from work (Ramadubu, 2011).

- Accumulated leave: Except under special conditions or due to extenuating circumstances, when they may be allowed leave during school terms, teachers are only entitled to take their accumulated leave during school breaks.

- Study leave: Teachers on study leave may be allowed time off work to concentrate on their studies, for example, to prepare for examinations.

- Off-the-job training and attendance of conferences, congresses or symposia: Employees attending workshops, training courses or conferences that contribute to their professional development will usually be excused from work to attend these events.

- Extracurricular activities: Workers such as teachers involved in activities that fall outside the strict scope of teachings, such as clubs or coaching sport may legitimately be absent from the classroom due to competitions among schools. However, such activities may also serve as a pretence for teachers who are dissatisfied with their core duty to absent themselves from the classroom.

- Organisational culture: If an organisation entertains an absencetolerant culture, its employees may regard this as a hidden benefit, an opportunity that they dare not miss. To combat this, some organisations, especially in the private sector, follow a 'no work, no pay' policy, whereby employees are paid for actual time spent at the workplace and sick leave does not apply.

- Poor supervision, control and management: Some organisations have ineffective systems to monitor and record work attendance, and employees may take advantage of this poor supervision to absent themselves from work without proper permission or legitimate reasons.

- Unmet expectations: Employees may absent themselves from work if their expectations of the workplace fail to realise. In such cases, absenteeism may be a form of expressing disapproval of management.

- Job-person match: Employees' skills sets may not match the tasks they are given, which may create boredom or frustration, because they feel that they are not using their skills or that their jobs are a waste of time. Such feelings may result in a decision to stay away from work.

- Frequent job transfers: When employees are frequently transferred from one department or location to another, much productive time will be lost to the time spent on travelling, moving and settling into the new environment.

- Workplace abuse: Burke (2003) mentions a California case where a jury awarded $\$ 30$ million in damages against the 450-store Ralph's supermarket chain for failing to stop the systematic and long-term sexual harassment and physical and emotional abuse of female employees by a 
store manager. During the trial, the jury heard of repeated incidents involving fondling, foul language and racial slurs, and the throwing of everything from pens to telephones. Although this may represent an extreme case of workplace abuse, it is not difficult to see that employees may well prefer to absent themselves from work rather than face such treatment. As far as teachers are concerned, the most common form of workplace abuse reported is foul language and the threat of physical violence directed against them by students. This creates a hostile environment which many teachers will avoid by reneging on their duties in order to protect themselves (Burke 2003).

High absenteeism and labour turnover figures may be an indication of discontent within an organisation (Greenburg \& Baron 1995), with disgruntled employees communicating their dissatisfaction with management by absenting themselves. Organisations should, therefore, do careful introspection in considering whether absenteeism issues within their ranks are perhaps a manifestation of genuinely unhappy employees. Employees who are dissatisfied with their work or work environment display lower commitment and are at a greater risk of leaving the profession (Evans 2001).

\section{Risk Analysis Concerning Absenteeism}

Absenteeism is a factor that must be addressed and curbed by management because if not monitored, it will breed unprecedented events such as risks in the organisation. A careful analysis of factors that lead to employees absconding from work should be counter measured. According to Fraser and Simkins (2010), risk analysis is a tool that can be used to draw a picture of a risk and provide the manager with all necessary information concerning that particular risk. After acquiring adequate information about the risk, the decision maker can then know what plan of action to take to mitigate the risks. Risk analysis can rely on mathematical computations such as statistics to give clear understanding or just a qualitative study after careful summation is made from other literature concerning a particular risk. Some disciples such as Decisionmaking studies can help managers with estimates and projections so that they can be able to take calculated risks (Fraser and Simkins 2010). Repeated events and tendencies such as absenteeism can become handy in analysing risks that can be proacted upon. Risk analyses operate on the concept of cause analyses, whereby the cause of reaction to a certain phenomenon is studied and curbed, absenteeism is, therefore, such a case.

\section{Conclusions}

The literature study has explored absenteeism as a measurable problem in organisations, to a large extent, a measure of the degree to which an employee's needs are met by his or her job or not. Employees who perceive their jobs as unrewarding or failing to live up to their expectations will show an increased tendency to absent themselves from the workplace. The nature of the work and the work environment affect job satisfaction hence lead to staying away from work. Enriching jobs that provide employees with a variety of tasks can, therefore, result in greater satisfaction than routine ones which will encourage employees to be present at work. The type of supervision also affects employees; a coercive boss will tend to demoralise his employees. As regards absenteeism, the literature indicates that it has disastrous effects on the individual, his fellow employees, the organisation and its clients. In a school scenario, teacher absenteeism not only adversely affects the performance of students, but also puts pressure on an absent teacher's colleagues, who have to assume his duties, and demoralises them. Also, it tends to predispose the absent teacher to even more absenteeism to avoid the pressure of the heightened workload that awaits him on his return. However, there are unavoidable reasons such as sicknesses which organisations need to come up with better solutions such as a doctor on call for employees of a particular enterprise. In short, systematic employee absenteeism is often a sign of job dissatisfaction and understanding the root causes, trends and predictors may go a long way towards creating practical solutions for curbing this problem. In addition to the above study, further quantitative studies are recommended in order to assess the impact of absenteeism in the workplace critically.

\section{References}

- Al-Fudail, M., \& Mellar, H. Investigating teacher stress when using technology. Computers and education. 2008 (51), 1103-1110. Crossref

- $\quad$ Arnell, A.T. \& Brown, S.L. Measuring the effect teacher absenteeism has on student achievement at a "urban but not too urban:" Title I Elementary School International Journal of Humanities and Social Science. 2012,2 (17): 172-183.

- Couglan Clark, A., \& Oswald, A. 2004. Satisfaction and comparison income [J]. Journal of Public Economics, 2004(61),359-381.

- Evans, L. "Understanding teacher morale and job satisfaction,". Teaching and Teacher Education, 2001, Vol. 13, No. 8, pp. 831-845. Crossref

- Fraser, J. and Simkins, B. Enterprise Risk Management New Jersey: John Willy and sons Inc, 2010.

- Goodman, P.S. and Atkin, R.S. Absenteeism: New approaches to understanding, measuring, and managing employee absence. San Fransisco: Josey-Bass, 1994.

- Greenglass, E.R, \& Burke, R.J. Teacher Stress. New York: Taylor and Francis, 2003. Crossref

- Grobler, P., Warnich, S., Carrell M.R., Elbert, N.F. and Hatfield, R.D. Human resource management in South Africa, 3rd Edition. London: Thomson Learning, High Holborn House; 50-51 Bedford Row, 2006.

- Kaman, R. L. Worksite health promotion economics: consensus and analysis. Buffalo: New York, 1995.

- Kyriacon, C. Teacher Stress: Directions of future research. Education review, 2001(53),27-35.

- Levy, A. An examination and baseline report on some aspects of absenteeism in South Africa. The Vanishing Workforce. Pretoria: Juta \& co, 2006.

- Maslach, C., Schaufeli, W.B., \& Leiter, M. P. Job burnout Annual Review Psychology, 2003(52), 397-422. Crossref

- McHugh, M. Employee absence: an impediment to organizational health in local government. International Journal of Public Sector Management, 2001, Volume 14. Crossref

- Nel, P.S. Gerber, P.D. van Dyk, P.S. Haasbroek, G.D. Schultz, H.B. Sono, T. Werner, A. Human Resource Management. Oxford: Oxford University Press, 2001

- Nel, P.S., Werner, A., Haasbroek, G.D., Poisat, P., Sono, T. and Schultz, H. Human Resources Management7th edition. Cape Town: Oxford University Press, 2008.

- Ramadubu, D. Teachers down tools. Botswana Gazette, 2011(7), 10 November.

- Robbins, S.P and Judge, T.A. Organisational Behaviour. 12th.ed. New Jersey: Pearson Education, Incorporated, 2004.

- Schultz, H., \&Schultz , J. Industrial Psychology: Science and Practice. Pretoria: Van Schaik Publishers, 2006.

- Senel, B \& Senel, M. The cost of absenteeism and the effect of demographic characteristics and tenure on absenteeism. Interdisciplinary Journal of Contemporary Research in Business, 2012,4 (4): 1142-1151.

- South Africa. Labour relations Act (Act 66 of 1995). 
- Swarnalatha, C. \& Sureshkrishna, G. Absenteeism - a menace to organizationin building job satisfaction among employees in automotive 